\title{
Comparison of Intra-Venus Ranitidine with Pantoprazole in Patients with Epigastric Pain Referring to Emergency Department
}

\author{
Iraj Goli Khatir, Fatemeh Jahanian*, Nooshin Varedi, Hamed Amini Ahidashti, \\ Seyyed Hosein Montazar, Seyed Mohammad Hosseininejad
}

Department of Emergency Medicine, Faculty of Medicine, Mazandaran University of Medical Sciences, Iran

Received September 17, 2019; Revised November 12, 2019; Accepted November 19, 2019

Copyright $\mathrm{C} 2020$ by authors, all rights reserved. Authors agree that this article remains permanently open access under the terms of the Creative Commons Attribution License 4.0 International License

\begin{abstract}
Background and aim: Epigastric pain episodes are one of the most common complaints of patients referring to the emergency departments worldwide. The purpose of this study was to compare the effects of ranitidine and pantoprazole on epigastric pain in the emergency department. Materials and Methods: This randomized clinical trial (RCT) study was performed on 100 patients (50 patients in each study arm) with epigastric pain complaints referred to emergency department of Imam Khomeini Educational Hospital in Sari in 2017. Patients older than 18 years of age with an epigastric pain with early diagnosis of dyspepsia and a visual acuity score of $20 \mathrm{~mm}$ high (VAS) were included. Patients were enrolled in two treatment groups: single venous dose of pantoprazole $40 \mathrm{mg}$ and single dose of ranitidine $50 \mathrm{mg}$. The pain score was recorded 30 and 60 minutes after the intervention. Results: The findings showed that in the pantoprazole group: $9.4 \%$ dyspepsia and $37.5 \%$ pancreatitis and $12.5 \%$ gastroenteritis and $40.6 \%$ asymptomatic. Before the intervention, the pain group had a pain score of 10.8 and 8.16 in the pantoprazole group. There were no differences between the two groups $(\mathrm{P}=$ 0.888 ), but after treatment, significant difference were observed in each of the groups after the use $(\mathrm{P}<0.001)$. Also, the comparison of the two groups after treatment showed that there was a significant difference in pain severity between the two treatment groups $(\mathrm{P}<0.001)$. Conclusion: The results of this study have revealed that Ranitidine and Pantoprazole effectively improve initial epigastric pain, but ranitidine is more effective.
\end{abstract}

Keywords Ranitidine, Pantoprazole, Dyspepsia, Pain, Emergency

\section{Introduction}

Epigastric pain is one of the most common complaints in patients referring to emergency departments. It may have different reasons. The most important reasons are cardiac dysfunction and gastrointestinal disorders. Gastrointestinal epigastric pain has many symptoms including bloating, nausea, vomiting, heartburn, reflux, or a set of these symptoms. [1] The prevalence of symptoms in the western countries was reported $20-30 \%$. In several studies, especially endoscopic researches, only about $20-30 \%$ of them were pathologically diagnosed, and the rest had no lesions. [2]

Papers have shown approximately $21 \%$ of people in Western countries have no ulcerative dyspepsia. In these patients, there is no structural dysfunction to justify the symptoms. [3] The pathogenesis of non-ulcerous dyspepsia is also unknown. [2, 4, 5] Recent researches focused on four factors: motor dysfunction, sensory impairment, Mucosa inflammation, Helicobacter infection, psychosocial and central nervous system changes [6].

Pantoprazole is a Proton pump inhibitor that is used to reduce gastric acid secretion in the treatment of acid-dependent disorders and indigestion. The use of this medicine is increasing. The reason is its greater effect on histamine receptor antagonists in the treatment of gastric acid-dependent disorders, including peptic ulcer. It has been recommended as the first treatment for most of the serious gastric acid diseases, such as erosive esophagitis, by the international guidelines. [1]

Ranitidine is a $\mathrm{H} 2$ receptor antagonist and it competitively inhibits the effect of histamine on $\mathrm{H} 2$ receptors in gastric wall cells. This effect prevents basic and nocturnal acid secretion. It also inhibits acid secretion result from histamine, food, amino acids, insulin and pantagastrin [1]. 
Kalantari and colleagues studied the effect of Omeprazole and Ranitidine in treating duodenal ulcer. This study showed that omeprazole was effectively better than ranitidine in improving duodenal ulcer. Omeprazole could reduce $60 \%$ of the prevalence of the ulcer while ranitidine could reduce $26 \%$ [6].

Mason and colleagues studied the effect of Ranitidine and Omeprazole on dyspepsia. The results showed that Omeprazole could improve $61 \%$ of the disorder while Ranitidine could improve 40\% [7].

Serinken and colleagues compared the effect of $50 \mathrm{mg}$ intravenous Ranitidine with $40 \mathrm{mg}$ Pantoprazole. They concluded that the efficacy of intravenous pantoprazole was not significantly different from intravenous ranitidine in patients. The pain was reduced in both groups 30 and 30 minutes after the intervention [3].

Considering that the treatment of epigastric pain in emergency departments has not been studied in our region and despite of its high prevalence, therefore, the purpose of this article was to compare the analgesic effect of ranitidine and pantoprazole on epigastric pain in the patients referring to emergency department.

\section{Method}

This randomized clinical trial (RCT) was performed on 100 patients (50 patients in each group) with epigastric pain referring to emergency department of Imam Khomeini Hospital, Sari in 2017. The patients were divided to two groups randomly by computer. The patients and final evaluator were unaware of patient's allocation (double blinded). There was no possibility of masking for the doctor because the patients had emergent condition and emergent tests were needed.

According to Engin Senay [3] and colleagues' study (2016), sample size was calculated 50 patients for each group considering confidence interval of $95 \%$ and power of $80 \%$.

$$
\begin{gathered}
\mathrm{N}=2 \mathrm{~K} * \mathrm{SD} 2 / \mathrm{d} 2 \\
\mathrm{~N}=2 * 10.5 * 282 / 202 * 1.2=50
\end{gathered}
$$

\subsection{Inclusion and Exclusion Criteria}

Study population was consisted of patients over 18 years old who were diagnosed with epigastric pain and early diagnosis of dyspepsia and a visual acuity score of $20 \mathrm{~mm}$ (VAS). The primary diagnosis of dyspepsia was done by Emergency Medicine Specialist. The placebo was provided by the pharmacy department of university and given to patients by blinded nurse.

The exclusion criteria were pregnancy, VAS score $<20 \mathrm{~mm}$, other causes of dyspepsia such as acute cholangitis, acute myocardial infarction, and pancreatitis, unstable hemodynamic, history of anti-acid and H2 receptor blockers, and PPI one hour before admission in emergency department, having allergy to the medicines, dissatisfied with participating, and leaving the study.

The patients were divided into two groups A and B. group A received $40 \mathrm{mg}$ intravenous pantoprazole which was diluted in 100cc Normal Saline and was infused during 2-4 hours. Group B received 50 mg intravenous Ranitidine diluted in 100cc Normal Saline and infused during 2-4 hours.

Data gathering was done using a questionnaire including demographic data such as age, sex, history of smoking, consuming analgesics, previous gastrointestinal diseases, and getting infected by H-pylori. Another questionnaire was used to record VAS score 30 and 60 minutes after intervention and side effects such as Headache, dizziness, blurred vision, rash, Diarrhea, palpitations, hypoglycemia, insomnia, anxiety, hyperglycemia, bloating, nausea and vomiting.

Data were analyzed by SPSS software 18. Quantitative data were described with mean and standard deviations and qualitative data with frequency and percentages. Studying data distribution was performed by histogram and Kolmogorov-Smirnov or Shapiro-Wilkes tests. Mean of VAS was calculated Using Mann-Whitney U Test and Independent T-Test. P value of less than 0.05 was defined as significant.

\section{Results}

This study was conducted to compare the effects of ranitidine and pantoprazole in patients with epigastric pain who referred to emergency department of Imam Khomeini Hospital (Sari, Iran) during 2017. One hundred patients over 18 years old were randomly entered into two groups. Non-parametric tests were used because of not being equal variances. Comparison between the groups was done using Mann-Whitney test and intra-group comparison was used to compare pain severity before and after treatment by Wilcoxon.

The mean age in Ranitidine group was $46.76 \pm 17.044$ and in pantoprazole group was $48.88 \pm 16.184$ ( $\mathrm{p}$-value $=0.459$ ).

Fisher's exact test was used for analyzing the qualitative data. For analyzing the quantitative data which had not normal distribution, nonparametric test was used. Comparison between groups was done using U-Mann-Whitney test and Wilcoxon test was used to compare pain severity before and after treatment.

Table 1 shows the results of comparison the variables between two groups. 
Table 1. The results of comparison the variables between two groups

\begin{tabular}{|c|c|c|c|c|c|c|}
\hline \multirow{2}{*}{\multicolumn{2}{|c|}{ variables }} & \multicolumn{2}{|c|}{ Ranitidine } & \multicolumn{2}{|c|}{ Pantoprazole } & \multirow{2}{*}{ p-value } \\
\hline & & \multirow{2}{*}{$\begin{array}{c}\text { frequency } \\
34\end{array}$} & \multirow{2}{*}{$\frac{\text { percent }}{50}$} & \multirow{2}{*}{$\begin{array}{c}\text { frequency } \\
6\end{array}$} & \multirow{2}{*}{$\begin{array}{c}\text { percent } \\
18.8\end{array}$} & \\
\hline $\operatorname{sex}$ & Male & & & & & \multirow{2}{*}{0.003} \\
\hline & female & 34 & 50 & 26 & 81.3 & \\
\hline \multirow{2}{*}{ smoking } & smoker & 3 & 4.4 & 1 & 3.1 & \multirow{2}{*}{0.617} \\
\hline & Non-smoker & 65 & 95.6 & 31 & 96.9 & \\
\hline \multirow{2}{*}{$\begin{array}{l}\text { Analgesic } \\
\text { consumption }\end{array}$} & Yes & 36 & 52.9 & 8 & 25 & \multirow{2}{*}{0.009} \\
\hline & no & 32 & 47.1 & 24 & 75 & \\
\hline \multirow{2}{*}{ H-pylori infection } & Yes & 16 & 23.5 & 4 & 12.5 & \multirow{2}{*}{0.198} \\
\hline & no & 52 & 76.5 & 28 & 87.5 & \\
\hline \multirow{2}{*}{ GI disorder } & Yes & 27 & 39.7 & 9 & 28.1 & \multirow{2}{*}{0.260} \\
\hline & no & 41 & 60.3 & 23 & 71.9 & \\
\hline \multirow{2}{*}{ GI pain } & Yes & 68 & 100 & 32 & 100 & \multirow{2}{*}{-} \\
\hline & no & 0 & 0 & 0 & 0 & \\
\hline \multirow{2}{*}{ headache } & Yes & 0 & 0 & 0 & 0 & \multirow{2}{*}{-} \\
\hline & no & 68 & 100 & 32 & 100 & \\
\hline \multirow{2}{*}{ Dizziness } & Yes & 0 & 0 & 0 & 0 & \multirow{2}{*}{-} \\
\hline & no & 68 & 100 & 32 & 100 & \\
\hline \multirow{2}{*}{ Blurred vision } & Yes & 0 & 0 & 0 & 0 & \multirow{2}{*}{-} \\
\hline & no & 68 & 100 & 32 & 100 & \\
\hline \multirow{2}{*}{ Nausea and vomiting } & Yes & 14 & 20.6 & 10 & 31.3 & \multirow{2}{*}{0.316} \\
\hline & no & 54 & 79.4 & 22 & 68.8 & \\
\hline \multirow{2}{*}{ Rash } & Yes & 0 & 0 & 0 & 0 & \multirow{2}{*}{-} \\
\hline & no & 68 & 100 & 32 & 100 & \\
\hline \multirow{2}{*}{ Diarrhea } & Yes & 0 & 0 & 0 & 0 & \\
\hline & no & 68 & 100 & 32 & 100 & - \\
\hline hynoclycemia & Yes & 0 & 0 & 0 & 0 & \\
\hline nypogiуcemia & no & 68 & 100 & 32 & 100 & - \\
\hline bloting & Yes & 0 & 0 & 4 & 12.5 & \\
\hline Droating & no & 68 & 100 & 28 & 87.5 & 0.009 \\
\hline & Yes & 0 & 0 & 0 & 0 & \\
\hline palpitation & no & 68 & 100 & 32 & 100 & - \\
\hline
\end{tabular}

According to table 1, two groups were not homogeneous in $\operatorname{sex}(\mathrm{p}=0.003)$ there was also a significant difference between the groups in analgesic consumption which was higher in ranitidine group $(\mathrm{p}=0.009)$. According to similar situation about occurrence the GI pain, headache, dizziness, blurred vision, rash, diarrhea, hypoglycemia, and palpitation in both groups, therefore comparison was not possible.

Primary and secondary diagnosis is shown in table 2 using Fisher exact test. 
Table 2. Primary and secondary diagnosis using Fisher exact test

\begin{tabular}{|c|c|c|c|c|c|c|c|c|}
\hline \multirow{2}{*}{\multicolumn{2}{|c|}{ diagnosis }} & \multicolumn{2}{|c|}{ Ranitidine } & \multicolumn{2}{|c|}{ Pantoprazole } & \multicolumn{2}{|c|}{ total } & p-value \\
\hline & & frequency & percent & frequency & percent & frequency & percent & \multirow{4}{*}{$<0.001$} \\
\hline \multirow{3}{*}{$\begin{array}{l}\text { Primary } \\
\text { diagnosis }\end{array}$} & dyspepsia & 68 & 100.0 & 24 & 75.0 & 92 & 92.0 & \\
\hline & pancreatitis & 0 & 0.0 & 8 & 25.0 & 8 & 8.0 & \\
\hline & total & 68 & 100.0 & 32 & 100.0 & 100 & 100.0 & \\
\hline \multirow{5}{*}{$\begin{array}{c}\text { Secondary } \\
\text { diagnosis }\end{array}$} & dyspepsia & 17 & 25.0 & 3 & 9.4 & 20 & 20.0 & \multirow{5}{*}{$<0.001$} \\
\hline & pancreatitis & 0 & 0.0 & 12 & 37.5 & 12 & 12.0 & \\
\hline & gastroenteritis & 4 & 5.9 & 4 & 12.5 & 8 & 8.0 & \\
\hline & No symptom & 47 & 69.1 & 13 & 40.6 & 60 & 60.0 & \\
\hline & total & 100 & 100.0 & 32 & 100.0 & 100 & 100.0 & \\
\hline
\end{tabular}

The results showed that primary diagnosis for all participants of ranitidine group was dyspepsia, while the diagnosis changed into $25 \%$ dyspepsia, $5.9 \%$ gastroenteritis, and $69.1 \%$ no symptom after the intervention. In other group primary diagnoses were $75 \%$ dyspepsia and $25 \%$ pancreatitis. After the intervention the diagnoses were $9.4 \%$ dyspepsia, $37.5 \%$ pancreatitis, $12.5 \%$ gastroenteritis, and $40.6 \%$ no symptom. $(\mathrm{p}<0.001)$

The pain score was compared before and after the intervention and the results is shown in table 3 .

Table 3. Pain score before and after the intervention

\begin{tabular}{|c|c|c|c|c|c|}
\hline \multirow{2}{*}{ Pain score } & \multicolumn{2}{|c|}{ Ranitidine } & \multicolumn{2}{c|}{ Pantoprazole } & \multirow{2}{*}{ p-value } \\
\cline { 2 - 5 } & mean & SD & mean & SD & \\
\hline $\begin{array}{c}\text { Before } \\
\text { intervention }\end{array}$ & 8.10 & 2.11 & 8.16 & 2.03 & $<0.001$ \\
\hline $\begin{array}{c}\text { After } \\
\text { intervention }\end{array}$ & 1.35 & 1.44 & 3.88 & 2.63 & \\
\hline
\end{tabular}

\section{Discussion}

This study was conducted to compare the effect of pantoprazole and ranitidine on epigastric pain induced by early dyspepsia in adult patients. They were randomly assigned to two groups: pantoprazole group with 52 patients $36.4(0.91 \%)$ and ranitidine group with 43 patients (30.1\%).

In this study, it was shown that pantoprazole was not better than ranitidine in controlling dyspeptic pain in emergency department. There are several therapeutic methods for primary gastritis and peptic ulcers such as SPPI, anti-acids, and $\mathrm{H} 2$ receptor blockers. But the response to the treatment is not clear enough.

Proton-pomp inhibitors (PPIs), $\mathrm{H}_{2}$ receptor antagonists $\left(\mathrm{H}_{2} \mathrm{RAs}\right)$ and anti-acids are the most common agents used for the treatment of dyspepsia, peptic ulcer and gastritis. A Cochrane meta-analysis reported that PPIs are more effective than $\mathrm{H}_{2}$ receptor blockers and anti-acids [10]

Engin Senay and colleagues compared intravenous pantoprazole and ranitidine in patients with dyspepsia presented to the emergency department. They compared the effectiveness of $50 \mathrm{mg}$ ranitidine and $40 \mathrm{mg}$ pantoprazole, given in a $100 \mathrm{~mL}$ saline solution by an intravenous rapid infusion within 2-4 minutes in patients with dyspepsia presented to the ED. Pain intensity was measured at baseline, 30 and 60 minutes after the drug administration. They concluded that intravenous pantoprazole and ranitidine are not superior to each other in ceasing dyspeptic symptoms at 30 and 60 minutes in the ED. [3] our results are similar to this study.

Musikatalora and colleagues compared the effect of pantoprazole-anti-acid with pantoprazole-anti-spasmodic. Selected patients with severe dyspeptic pain were randomized to treatment with a placebo, antacid, and antispasmodic (conventional group) or IV pantoprazole, antacid, and antispasmodic (pantoprazole group). The self-reported 100-mm visual analog scale score, adverse effects, and overall satisfaction were evaluated in 15-minute intervals for 60 minutes. They showed that they were not different and better than each other [7]

In our study, the improvement in Ranitidine group was $24 \%$ while in pantoprazole group was $39 \%$.

Vilke GM and colleagues studied viscous lidocaine versus benzocaine in a GI cocktail for dyspepsia. Patients 18 years or older were approached for participation when a GI cocktail was ordered by the Emergency Physician. Patients were randomized to equivalent doses of either Benzocaine or viscous Lidocaine in addition to $30 \mathrm{cc}$ of Maalox and $10 \mathrm{cc}$ of Donnatal. Assessment using a visual analog pain scale occurred at time intervals of $0,5,15$, and $30 \mathrm{~min}$. They showed no statistical differences between the Benzocaine and viscous Lidocaine groups in terms of the relief of symptoms at each of the assessment times. There were no adverse outcomes in either group [8] it was in line with our study.

According to our results, there was no headache, dizziness, hypoglycemia and nausea-vomiting in both groups, but floating was higher in pantoprazole group. Seray and colleagues showed similar result in their study [9].

Demetrashvili ZM and colleagues compared intravenous pantoprazole with intravenous ranitidine for prevention of rebleeding of peptic ulcers following initial endoscopic hemostasis. They investigated no statistically significant 
differences between the groups with regard to need for emergency surgery $(2,2 \%$ vs $6,8 \%)$, the length of hospital stay $(6,7 \pm 3,3$ vs $7,4 \pm 4,3 \mathrm{~d})$ and mortality $(0 \%$ vs $0 \%)$. After endoscopic treatment of bleeding peptic ulcers, intravenous pantoprazole is more effective than ranitidine for the prevention of rebleeding. [11]

Both PPIs and $\mathrm{H}_{2}$ receptor blocker are generally accepted as safe drugs. Our study showed that pantoprazole and ranitidine are not superior in reducing epigastric pain in the ED, but each is safe to use in the ED. Cost might be a matter of choosing the appropriate treatment. Further studies are needed to discover the right ways.

\section{Conclusions}

The results of this study showed that both ranitidine and pantoprazole effectively improve initial episodes of pain, but ranitidine is more effective than pantoprazole in improving epigastric pain. Also, rash, headache, dizziness, hypoglycemia were not observed. It seems that ranitidine can control epigastric pain in emergency patients. Also, the accuracy of this study can be checked in future trials with more sample size. Further investigations are needed to confirm the outcomes.

\section{Conflict of Interest}

Authors declare that there are no conflicts of interest.

\section{REFERENCES}

[1] Nawar EW, Niska RW, Xu J. National Hospital Ambulatory Medical Care Survey: 2005 emergency department summary. Advance data. 2007(386): 1-32. 2.

[2] Van Rensburg C, Barkun A, Racz I, Fedorak R, Bornman P, Beglinger $C$, et al. Clinical trial: intravenous pantoprazole vs. ranitidine for the prevention of peptic ulcer rebleeding: a multicentre, multinational, randomized trial. Alimentary pharmacology \& therapeutics. 2009; 29(5): 497-507.

[3] Senay E, Eken C, Yildiz M, Yilmaz D, Alkan E, Akin M, et al. Comparison of intravenous pantoprazole and ranitidine in patients with dyspepsia presented to the emergency department: a randomized, double blind, controlled trial. World journal of emergency medicine. 2016; 7(1):30.

[4] van Marrewijk CJ, Mujakovic S, Fransen GA, Numans ME, de Wit NJ, Muris JW, et al. Effect and cost-effectiveness of step-up versus step-down treatment with antacids, H2-receptor antagonists, and proton pump inhibitors in patients with new onset dyspepsia (DIAMOND study): a primary-care-based randomised controlled trial. Lancet (London, England). 2009; 373(9659): 215- 25.

[5] Delaney B, Ford AC, Forman D, Moayyedi P, Qume M. WITHDRAWN: Initial management strategies for dyspepsia. The Cochrane database of systematic reviews. 2009(4): Cd001961.

[6] H k. Comparison of ranitidine and omeprazole in 100 patients suffered dyspepsia. Sabzevar MEDICAL UNIVERCITY journal. 1382; 10(1): 6-12.

[7] Musikatavorn K, Tansangngam P, Lumlertgul S, Komindr A. A randomized controlled trial of adding intravenous pantoprazole to conventional treatment for the immediate relief of dyspeptic pain. The American journal of emergency medicine. 2012; 30(9): 1737-42.

[8] Vilke GM, Jin A, Davis DP, Chan TC. Prospective randomized study of viscous lidocaine versus benzocaine in a GI cocktail for dyspepsia. The Journal of emergency medicine. 2004; 27(1): 7-9.

[9] Welling LR, Watson WA. The emergency department treatment of dyspepsia with antacids and oral lidocaine. Annals of emergency medicine. 1990; 19(7): 785-8.

[10] Delaney B, Ford AC, Forman D, Moayyedi P, Qume M. WITHDRAWN: Initial management strategies for dyspepsia. Cochrane Database Syst Rev. 2009; 4: CD001961.

[11] Demetrashvili ZM, Lashkhi IM, Ekaladze EN, Kamkamidze GK. Comparison of intravenous pantoprazole with intravenous ranitidine in peptic ulcer bleeding.Georgian Med News. 2013 Oct; (223): 7-11. 